\title{
The boundaries of the firm: why do sugar producers outsource sugarcane production?
}

\author{
Kurt Sartorius, Johann Kirsten
}

\section{Introduction}

The incidence of outsourcing, a form of vertical co-ordination, has increased rapidly in recent decades as firms world wide have allegedly shed non-core business (Widener and Selto, 1999; Langfield-Smith and Smith, 2003). It is widespread in industries such as the banking, defense, telecommunication, automobile, petrochemical, textile, construction, book publishing, information technology and motion picture sectors (Cutts, 1992; McAfee, 1999; van den Bogaard and Spekle, 2003). The structure of agricultural supply chains has also witnessed profound change. Typically, these chains begin with the farmer who supplies a raw commodity to the processor. The processor, in turn, adds value to the raw commodity before selling the manufactured product to a wholesaler or retailer who sells the final product to the consumer. Because of increasingly stringent consumer requirements there is a need for much higher levels of managed control right across the supply chain in order to configure consumer requirements from farm to table (Hayes et al., 2000). Increasingly, the production of raw commodities is being outsourced on a contract basis and it is estimated in the United States that more than one in every 10 farmers is contracted to agribusiness (Rhodes, 1993; Colchao, 1999). The impact of these structural changes has resulted in fewer larger farms, the concentration of farming, increased specialisation and closer ties with processors (Frank and Henderson, 1992; Rhodes, 1993; Schrader and Boehlje, 1996; Pasour, 1998). The selection of outsourcing asa governance form in the agricultural supply chains ofdeveloped countries appearstobedrivenby profit (Baumol, 1997) as firms seek technological economies, economies of scale, transaction cost economies or bargaining advantages (Royer, 1995). By contrast, outsourcing in developing countries is often driven by a hybrid of normal economic objectives, as well as the need to comply with governmental, societal or welfare goals (Rehber, 1998). The purpose of this study is to demonstrate that the use of transaction cost analysis can contribute to a better understanding of outsourcing from the perspective of the outsourcer.

The changed structure of supply chains is presumed to be a strategic response to new technologies and market conditions (Merchant, 1998; Anthony and Govindarajan, 2001). High levels of competition and change influence the need for responsive strategies and strategy requires firms to adopt organisation structures that are able to react to changes in the market conditions (Abernathy and Lillis, 2001). In this respect, the resource-based theory of strategic management sees the firm concentrating its limited resources on core activities and divesting out of non-core activities in order to determine the boundaries of the firm (Coase, 1937; Mahoney, 1992; Mahoney and Pandian, 1992; Widener and Selto, 1999). An increasing number of sugar producers in Southern Africa have outsourced sugarcane production for the following reasons. Firstly, these companies believe their core capabilities lie in sugar production and not the growing of sugarcane. Secondly, they feel obliged to outsource sugarcane production as a way to contribute to the restructuring of the farm sector because many African communities were historically excluded 
from commercial agriculture. In this respect, sugarcane quotas have mostly been outsourced on the basis of a long-term contract that partially specifies the terms and conditions of supply. In certain instances, sugar manufacturers have also unbundled their own sugarcane estates as a component of their strategic plans to expand the involvement of, mostly, small-scale African suppliers. The research question is, however, should these firms outsource sugarcane production given the nature of the activities involved? Secondly, if sugarcane is outsourced what type of contract or organisation structure should be selected to co-ordinate these activities?

In general, this study aims to contribute to a better understanding of the relationship between economic theory and the practice of management accounting in response to the recommendations of Burns and Scapens (2000) and Spekle (2001). More specifically, this study aims to contribute to the knowledge of outsourcing by using a transaction cost analysis framework as an approach to determine whether or not an activity should be purchased or made. This contribution will confirm and expand the arguments of Roodhooft and Warlop (1999), and Joslin (2003) who examine certain features of transaction cost theory to guide the make versus buy decision. This study will also expand the conclusions of Widener and Selto (1999) and Van der Meer-Kooistra and Vosselman (2000) by contributing to a better understanding of how outsourced activities should be structured by the outsourcer. Finally, this study will strengthen the conclusions of van den Bogaard and Spekle (2003) who suggest that the suitability of a strategy-based structure can be tested by adopting a TCA approach to determine the optimum structure.

The outline of the rest of the study commences with a debate on the economics of the make or buy decision in Section 2 before discussing the economics of organisation structure in Section 3 and the methodology and data in Section 4. A case study is developed in Section 5 and the principal research questions are tested in Section 6. Section 7 discusses the results against the backdrop of outsourcing research literature. Finally, Section 8 develops a summary and conclusion before suggesting some future directions in related research.

\section{The make or buy decision}

The principal objective of organising commercial transactions is assumed to be the economising of the sum of production and transaction cost. In the absence of transaction cost the firm would buy goods and services because the bureaucratic costs of internal procurement would be avoided. Conversely, as transaction costs increase the firm begins investigating self-producing the necessary goods and services (Williamson, 1979). The principal reason for outsourcing an activity (goods orservices), from a transaction cost theory perspective, is outlined in the study of Coase (1937) who explained that certain activities are better co-ordinated by the market place than within the boundaries of the firm. In this regard, the increased efficiency of the market place offsets the bureaucracy costs of self-production. The management accounting literature, as summarised by Van der Meer-Kooistra and Vosselman (2000), Widener and Selto (2000) and Vosselman (2002), largely supports the contention that firms outsource activities to minimize total cost because:

- Outsourcing allows the firm to focus on core activities and avoid in-house duplication of support facilities.

- Contracting out reduces cost because of economies of scale achieved by the supplier.

- External firms are more efficient and market orientated with respect to certain non-core activities.

- In-house non-core activities increasingly require excessive training. 
- An increased demand for production flexibility requires firmstoconcentrate on production not ancillary activities.

- Firms outsource activities to reduce reliance onpeople and to reduce fixed cost and replace with variable cost.

The traditional management accounting literature has often been criticised because it sees the firm as an input-output function whose limited properties are described by neo-classical theory (NC). More specifically, neo-classical theory views the make buy problem solely in terms of a comparison of production cost versus purchasing cost and assumes all conditions are known and that these conditions are conveyed by market prices. The traditional management accounting literature, therefore, ignores certain costs that are incurred in the outsourcing decision because of the bounded rationality of the participants, opportunism and information asymmetry (Roodhooft and Warlop, 1999; Joslin, 2003). NC also assumes that the products can be standardised and ignores the issue of supplier reliability. In this regard, NC ignores the fact that the co-ordination of the purchase transactions can influence idiosyncratic properties that further contribute to an inability to standardise the product. In reality the outsourcing decision is influenced by opportunism and certain suppliers will perform better than others. In conclusion, neoclassical theory ignores the interplay between cost and the exchange characteristics of opportunism, asset specificity, uncertainty and the frequency of transactions (Anderson et al., 2000; Van der MeerKooistra and Vosselman, 2000).

\section{Transaction cost analysis (TCA)}

A transaction is described as occurring when goods or services are transferred across a technologically separable interface where these interactions occur as a result of technology, the division of labour, locations, markets or people. One stage of activity terminates and another begins (Rowlinson, 1997). Transactions can involve discrete market transactions, hierarchical managerial transactions, recurrent contract transactions or relational transactions (Ring and van den Ven, 1992). Transaction cost economics attempts to explain that certain activities are better co-ordinated in the market place whilst others should be co-ordinated within the firm hierarchy in order to minimise transaction cost. Transaction cost analysis (TCA) also assumes that all activities to create wealth can be seen in terms of some form of contract. Because these activities have different characteristics different types of contracts are better suited to co-ordinating the parties involved (Coase, 1937; Williamson, 1975, 1981). In this regard, the firm can be viewed as a nexus of internal and external contracts that co-ordinate activities both inside and outside the firm. A key feature of TCA is the matching of appropriate contract structures with the activities being coordinated in order to minimise transaction cost (Barney and Ouchi, 1988; Demsetz, 1988; Williamson, 1988; Reve, 1995; Groenewegen, 1996; Khalil, 1996; Zylbersztajn and Farina, 1999). Transaction costs in integrated agricultural markets include the bureaucratic costs of managing, communicating and coordinating integrated production, processing and marketing activities. Other transaction costs include motivation costs, the cost of worker inefficiencies and the legal costs of monitoring long-term contracts (Hayes et al., 2000).

Transaction cost economics can be likened to the theory of optimal contracts where the contracts are extremely sensitive to minor changes in the personal characteristics of the contracting parties including risk, information, collateral and assets (Seifert and Priddat, 1995). 
Transaction costs in a contracting arrangement occur because contractual hazards in the form of opportunism and bounded rationality result in incomplete contracts and hold ups. These conditions of uncertainty can occur because of the nature of the goods and services being transacted, a lack of commitment by the parties, information asymmetry or a situation where asset specificity exists. Asset specificity occurs when one of the parties to the contract can be exploited by the other because they have acquired assets that make them dependent on the relationship. This characteristic describes the degree to which the contract arrangement is linked to the specialised physical capital, site specific assets, human assets, co-ordination or temporal specificity requirements of one of the contracting parties. The presence of asset specificity, thus, increases the possibility of opportunistic behaviour by one party and a degree of dependency by the other party and, therefore, increases the cost of contracting (Klein et al., 1988; Williamson, 1988; Foss, 1995; Peterson and Wysocki, 1998). Contract cost can also be affected by the level of trust that exists between the contracting parties (Ring and van den Ven, 1992; Anderson et al., 2000) as well as by commodity specific cycles that affect certain industries in cyclical patterns (Ruth et al., 1998). These conditions result in increased levels of cost because the contracting parties are obliged to gather and disseminate incremental

Table 1

Economising Transaction Costs

\begin{tabular}{llll}
\hline Frequency & Asset specificity & & \\
\cline { 2 - 4 } & Low asset specificity & Medium asset specificity & High asset specificity \\
\hline Occasional & Classical contracting & Neo-classical contracting & Neo-classical contracting \\
Frequent & Classical contracting & Bilateral relational contract & Unified relational contract \\
\hline
\end{tabular}

Source: Williamson (1979).

information, as well as take the necessary steps to avoid being exploited (Williamson, 1975, 1981; Reve, 1995; Zylbersztajn and Farina, 1999).

The operationalisation of TCA, illustrated in Table 1, seeks to economise the sum total of a firm's production expense and its transaction costs by selecting an appropriate structure to coordinate the relevant activities both inside and outside the firm's boundaries. The appropriate structures are chosen by matching specific contract forms with specific transaction characteristics in order to minimise transaction cost (Williamson, 1975, 1979; Mahoney, 1992; Peterson and Wysocki, 1997, 1998; Hobbs and Young, 1999). Four different contract forms can be employed to procure goods and services for the firm. These contract forms include classical contracting, neoclassical contracting, bi-lateral relational contracts and unified relational contracts. The choice, however, of one of these contract structures is determined by the exact conditions of the exchange relationship. The conditions or contract characteristics that persist with respect to any exchange of goods and services are primarily a function of the frequency and uncertainty of the transactions together with the degree to which a party to the contract has invested in idiosyncratic assets that are of little value outside the exchange relationship (asset specificity). If a measure of uncertainty is assumed in the exchange relationship then various levels of frequency and asset specificity will create contract conditions that are suited to specific forms of contracting. For example, an infrequent transaction of standardised goods that require no specific investment in assets by either party would be most cost effectively acquired by way of a classical contract or open market trading. The reason for this is that the contract conditions can be fully specified before the exchange takes place 
and little scope for opportunism exists. Conversely, the frequent exchange of complex goods in conditions where one of the parties has invested in highly idiosyncratic assets are best coordinated by a relational contract structure that would be optimally accommodated in the fully integrated environment of the firm hierarchy. The reason for this is that that the repeated cost of attempting to write numerous classical type contracts would be excessive in conditions where bounded rationality, opportunism and information asymmetry are likely to exist.

\subsection{A conceptual framework for agricultural supply chains}

A methodology or conceptual framework to test whether or not to outsource an activity, as well as the suitability of a chosen outsourced governance structure can be developed by expanding the operationalisation conclusions of Williamson (1979) as outlined in the previous section. The methodology is constructed as follows: Firstly, the range of four contract forms suggested by Williamson (1979) are expanded to five and accommodated in a vertical co-ordination continuum of control structures illustrated in Table 2. Secondly, the transaction characteristics of frequency and asset specificity are expanded to include further contract conditions that relate to uncertainty. Each of the contract conditions are graded in terms of five levels of intensity so that they can be accommodated in one of the governance forms of the vertical co-ordination continuum. Finally, a conceptual framework is constructed in a table format, illustrated in Table 3, that matches each level of every transaction characteristic with a theoretically optimum governance form.

In order to practically test whether or not any activity should be outsourced the actual transaction characteristics of the outsourced activity need to be classified and graded in the same format as the conceptual framework. These graded characteristics are then plotted in the conceptual framework. A subjective assessment of the aggregated plotted characteristics will then suggest the suitability of a specific contract structure or governance form. If the governance structure suggested by the plotted outsourced activity characteristics appears to support the need for full vertical integration the goods or service are unlikely to be outsourced. Conversely, if the plotted contract characteristics are suited to being acquired on the open market the activity under consideration could be co-ordinated by an outsourcing structure.

\subsubsection{The vertical co-ordination continuum}

The range of governance structures for co-ordinating activities in an agricultural supply chain can be conceptualised as a continuum that runs from open markets to full vertical integration (Peterson and Wysocki, 1998). Similarly, Williamson (1979) proposed that any activity can be co-ordinated by a continuum of contracts that range from classical to relational. The governance structures can be combined with their contract forms to develop a vertical co-ordination continuum illustrated in Table 2. The five governance structures along the vertical co-ordination continuum include the spot market, specification contracting, a strategic alliance, formal co-operation and full vertical integration. These five governance forms, in turn, can be represented by classical contracting, two levels of neo-classical contracting, bilateral relational contracting and unified relational contracting. Different contract structures or governance forms are required to co-ordinate different activities. Typically, on the left hand side of the continuum the markets (classical contracting) handle exchanges more efficiently when these activities can be enforced legally, they are of short-term 
Table 2

The vertical coordination continuum

\begin{tabular}{|c|c|c|c|c|c|c|}
\hline $\begin{array}{l}\text { Characteristics of } \\
\text { market co-ordination }\end{array}$ & $\begin{array}{l}\text { Spot } \\
\text { market }\end{array}$ & $\begin{array}{l}\text { Specification } \\
\text { contract }\end{array}$ & $\begin{array}{l}\text { Strategic } \\
\text { alliance }\end{array}$ & $\begin{array}{l}\text { Formal } \\
\text { cooperation }\end{array}$ & $\begin{array}{l}\text { Vertical } \\
\text { integration }\end{array}$ & $\begin{array}{l}\text { Characteristics } \\
\text { of managed } \\
\text { co-ordination }\end{array}$ \\
\hline
\end{tabular}

Legal enforcement

Short term Limited information

Independence Ex

$\begin{array}{lll}\text { Classical } & \text { Neo-classical } & \text { Neo-classical } \\ \text { contract } & \text { contract } & \text { contract }\end{array}$

$\begin{array}{ll}\text { Bilateral } & \text { Unified } \\ \text { relational } & \text { relational } \\ \text { contract } & \text { contract }\end{array}$

Hierarchical enforcement ante control contract contract contract contract

Long term High level of information Interdependence Ex post importance No substitutes

Source: Peterson and Wysocki (1997, 1998).

Table 3

The conceptual framework

\begin{tabular}{|c|c|c|c|c|c|}
\hline \multirow[t]{4}{*}{ Contract characteristics } & Grade 1 & Grade 2 & Grade 3 & Grade 4 & Grade 5 \\
\hline & \multicolumn{5}{|c|}{ V.C. continuum } \\
\hline & $\begin{array}{l}\text { Classical } \\
\text { Contracting }\end{array}$ & $\begin{array}{l}\text { Neo classical } \\
\text { Contracting }\end{array}$ & $\begin{array}{l}\text { Neo classical } \\
\text { Contracting }\end{array}$ & $\begin{array}{l}\text { Bilateral } \\
\text { Relational }\end{array}$ & $\begin{array}{l}\text { Unified } \\
\text { Relational }\end{array}$ \\
\hline & Spot Market & $\begin{array}{l}\text { Specification } \\
\text { Contracting }\end{array}$ & $\begin{array}{l}\text { Strategic } \\
\text { Alliance }\end{array}$ & $\begin{array}{l}\text { Formal Co- } \\
\text { operation }\end{array}$ & $\begin{array}{l}\text { Full Vertical } \\
\text { Integration }\end{array}$ \\
\hline 1. Frequency & Low & Low-medium & Medium & High & Very high $X X$ \\
\hline $\begin{array}{l}\text { 2. Asset specificity } \\
\text { 3. Uncertainty }\end{array}$ & Low & Low-medium & Medium & High & Very high $X X$ \\
\hline Ability to walk away & Yes & Yes/lower & Less XX & Low & No \\
\hline Substitutes & Yes & Yes/less & Less & No & No XX \\
\hline Duration & Short & Short/medium & Medium & Long & Very long XX \\
\hline Ex ante control & High & Lower & Low & No & No $X X$ \\
\hline Ex post importance & Low & Low/medium & Medium & High & Very high XX \\
\hline Information shared & Low & Low/medium & Medium & High & Extensive XX \\
\hline Contract enforcement & Legal & Complex-legal & Complex XX & Bilateral & Hierarchy \\
\hline Summary & & & 2 & 0 & 7 \\
\hline
\end{tabular}

Based on: Williamson (1975, 1979, 1981), Mahoney (1992), Peterson and Wysocki (1997, 1998), Sartorius and Kirsten (2002).

nature, limited information is exchanged, the parties to the agreement are independent and the conditions of the agreement can all be specified on an ex ante basis.

Conversely, on the right hand side of the continuum, a fully integrated organisation structure (relational contracting) manages the exchange activities on a more cost efficient basis where the transaction characteristics of exchange indicate that the duration of the agreement is long term, the product is complex, no substitutes exist, high levels of information are shared and the parties are not independent. 


\subsubsection{Economising transaction cost: an outsourcer perspective}

A conceptual framework can be constructed by combining the vertical co-ordination continuum of Peterson and Wysocki (1997, 1998) with an expanded set of contract characteristics in a format illustrated in Table 3. At the intersection of each row and column the level of intensity of the relevant contract characteristic is matched with a suitable governance form. In order to determine the most suitable governance form to co-ordinate a specific activity the following steps are taken:

Firstly, each of the contract characteristics are graded in terms of five levels of intensity that match one of the five governance structures of the vertical co-ordination continuum. For example, where the outsourcer does not need to invest in any exchange related assets the level of asset specificity would be graded as a level one (1). Secondly, the graded contract characteristics are matched with an appropriate governance form by placing an entry in the appropriate column of the conceptual framework. Ignoring the impact of other exchange conditions, a level of intensity of one (1), for example, would match the governance form of spot market trading in the conceptual framework. Conversely, if the outsourcer has acquired very costly assets that are related to the exchange agreement, the level of asset specificity could be graded as five (5) and an entry placed in the conceptual framework at the intersection of the column marked full vertical integration and the row classified as asset specificity. Finally, the number of entries in each column are aggregated to indicate the most appropriate governance structure to co-ordinate the given set of transaction characteristics. If the aggregated scores of the columns are more weighted towards the left hand side of the table (market) then the contract conditions are likely to be more suitable for outsourcing. Conversely, if the aggregated score is more weighted to the right hand side of the table (the firm hierarchy) then the conditions are not suited to outsourcing.

For the sake of illustration, assume an agricultural processor is considering outsourcing the production of a raw commodity. The processor is well aware of the nature of the contract conditions of the supply arrangement because it self-produces the raw commodity. For each of these contract conditions the level of intensity is graded from one to five and XXs are placed in relevant columns in Table 3. The supply conditions are as follows: The processing capacity is large and the raw commodity is perishable so the firm will require very high levels of delivery frequency (5). Moreover, the firm has incurred a considerable investment to install the process facilities and this condition results in very high levels of asset specificity (5). There is a limited ability of the parties to walk away from the contract (3), there are no substitutes (5) for the raw commodity processed by the firm, the envisaged agreement would be required for a very long period (5) and high levels of information need to be shared (5) in order to ensure that the quality and timing of deliveries is maintained. Because of the long-term nature of the agreement and the volatile nature of raw commodity prices, as well as because the firm, on an ad hoc basis will need to provide certain inputs, it is impossible to specify the exact conditions of the supply agreement on an ex ante basis (5) and ex post importance is very high (5). Because of the duration and uncertainty of certain conditions it will be difficult to enforce the agreement on a purely legal basis and the parties will need to rely on mutual interest (3). An analysis of the aggregated contract conditions in Table 3 would collectively suggest that the raw commodity should not be outsourced because a score of seven entries has been recorded in the column marked full vertical integration and only two entries are recorded in the column marked strategic alliance. At the very least some type of hybrid structure, ranging between a strategic alliance and full vertical integration, is required to co-ordinate these activities. 
In support of this conclusion, the TCA literature overwhelmingly concurs that goods and services that are complex, require detailed levels of co-ordination and that are directly related to specific assets of the firm are less likely to be outsourced because they would most likely be procured under conditions of bounded rationality, opportunism and information asymmetry. The need for internalised control is further required if these transactions occur frequently over long periods of time. Conversely, activities that are standardised, not linked to specific assets in the firm and can easily be undertaken by a large number of suppliers are more likely to be acquired outside firm boundaries (Williamson, 1975, 1981; Anderson et al., 2000).

\section{Methodology and data}

The methodology uses a case study approach to test the research question, namely, whether sugar producers should outsource sugarcane production to small-scale farmers suppliers by way of unbundling company estates. The case study, moreover, employs the above conceptual framework (Fig. 3), developed from transaction cost theory, as a basis to select, process and analyse the data. A case study approach was employed because of the qualitative nature of the data in addition to the ability to explore a wider range of variables that influence the structure and performance of small-holder supply chains. A case study incorporating the sugar industry in Southern Africa was specifically selected because of a number of reasons. Firstly, the case study included a situation where the raw commodity processed was obtained from both the company's own estates, as well as from outsourced farmers. Secondly the sugar industry in Southern Africa has actively promoted smallholder outsourcing arrangements. Finally, the sugar industry is confronted with a typical Southern African agribusiness dilemma, namely the need to maximise profitability versus the pressure to contribute to redressing past injustice.

The data consist of the historical records of the Mhlume Sugar Company (MSCo), Swaziland and the Transvaal Sugar Company (TSB), Malelane, South Africa. The data from these organisations consist primarily of company and grower records between 1996 and 2001. The data were collected on a number of field trips between June and December 2001 and include a survey performed to determine the level of trust between the players in the MSCo sugarcane supply chain. The limitations of the data are primarily that the accounting systems of the two companies have not been able to differentiate between the transactions costs of the various sugarcane suppliers including their own company estates.

\section{Case study: sugarcane supply in Southern Africa}

A case study in the Swaziland sugar industry has been employed as a basis to test the research questions. The company is briefly introduced before its objectives and strategy are discussed with respect to the issue of structuring its sugarcane supply activities. The grower-processor supply chain is then described before outlining the detailed transaction characteristics of supply. In order to further illustrate the transaction characteristics of sugarcane supply, additional data from a South African sugar producing company is included. 


\subsection{The company}

The Mhlume Sugar Company (MSCo) of Swaziland was founded in 1958 and is $50 \%$ owned by the Commonwealth Development Corporation (CDC) and $50 \%$ by the Swaziland Government. MSCo produces a number of sugar products including raw brown sugar, refined sugar and molasses. The company currently employs in the order of 1865 permanent staff and contracted 314 seasonal staff in 2000/1. The early equity objectives of the owners, namely the Commonwealth Development Corporation and the Swaziland government, have resulted in extensive company inputs into the construction of a village, a school and the provision of medical facilities.

The company performance, illustrated in Table 4, indicates a steady growth in turnover and profitability. Return on capital employed (ROCE) climbed relatively steadily from 52\% in 1986/87 to a peak of $147 \%$ in $1996 / 7$ and thereafter declined to its current level. In the same period capital employed has increased from R 36.3 million to R 122.6 million, whilst cash on hand has declined. The mill operations generate larger profits than the agricultural division and the ratio between the mill and the agricultural operating margins is approximately $2: 1$. The factory performance indicates that the mill operations processed an

Table 4

Financial performance

Performance

2000/2001

Turnover

R351 million

PBIT

Ave ROCE (1986-2001)

Assets employed

Sugar production

R107.8 million

$82 \%$

R2billion (current cost)

150,000 tons

average annual tonnage of 1.25 million tons between 1982/1983 and 2000/2001 to produce around a 150,000 tons of sugar products annually.

\subsection{The company objectives}

The objectives of the Mhlume Sugar Company mainly focus on the optimisation of long-term wealth combined with the equity objectives of promoting the commercialisation of local farmers and the development of local communities. The company management has articulated the belief that the company should move away from its growing operations and focus on sugar manufacturing. The company has set a target of growing profit before interest and tax by $10 \%$ over the next 5 years. In addition to promoting the development of commercial sugarcane growers, the company intends continuing to provide a wide range of inputs to the local sugar growing community

\subsection{The proposed strategy}

The Mhlume Company strategy to increase profitability largely includes a proposal to merge 
their operations with the Simunye Sugar company, as well as expand mill capacity by $12 \%$. The merged operations are projected to rationalise capacity, produce incremental processing economies of scale and reduce facilities costs. The Mhlume company, moreover, has articulated the belief that its core competencies revolve around the manufacturing of sugar products and not in the growing of sugarcane. A strategy has, therefore, been developed that will allow the company to gradually divest out of its own sugarcane growing operations and promote the commercialisation of small-scale farmers. Firstly, the company is engaged in a project to expand small-scale farm supply by 6000 ha over the next 3 years. This supply will be outsourced to small-scale farmers by way of a specification contracting arrangement. The company is also considering unbundling part of its own company estates. Currently, the Mhlume Sugar Company self-produces $67 \%$ of all sugarcane processed on four company estates that occupy some 8791 ha. The company is currently considering unbundling an initial 2000 ha by outsourcing this production to small-scale farmers on a specification contract basis similar to the 6000 ha project. The proposed strategy will result in a gradual decrease in the percentage of fully integrated supply (the company estates), as the unbundling of estates commences alongside the expansion of small farm supply.

\subsection{The grower-processor supply chain}

The grower-processor supply chain, illustrated in Fig. 1, consists of a wide range of growers who produce and deliver sugarcane to the company mill. Because of the need to maintain optimum use of capacity, as well as the fact that sugarcane is a highly perishable product, the harvesting and delivery of this raw commodity is centrally co-ordinated by the factory mill which synchronises the activities of some 39 different supplier groups. These growers, including the company's own estates (67\% of supply), are mostly located within a 30-km radius of the company mills and deliveries are ensured by way of a network of all year secondary dirt and tar roads.

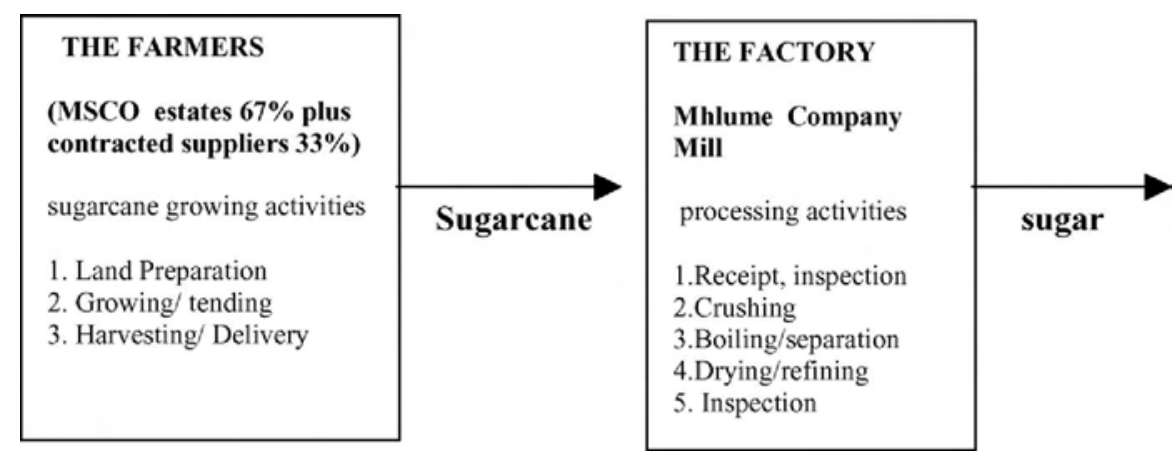

Fig. 1. The sugarcane supply chain.

\subsection{The contract characteristics of sugarcane supply: the outsourcer}

The delivery and processing of large volumes of a perishable commodity like sugarcane requires complex co-ordination of the activities of the growers with the optimum use of high fixed cost processing facilities. The classification and grading of these contract characteristics, illustrated in Table 5, has been developed on the basis of the methodology of Section 3.1. In order to better illustrate 
the contract characteristics of sugarcane supply, the case study has incorporated the records of an additional sugar producing company, namely, the Transvaal Sugar Company (TSB) of South Africa. The contract characteristics of sugarcane supply indicate high levels of frequency, asset specificity and an intermediate to high level of uncertainty. The volume of sugarcane deliveries to the mill and the volume of administration transactions with respect to the co-ordination of the growers affairs have been used as a proxy for the transaction characteristic of frequency. The cane receiving yards of MSCo and TSB co-ordinate in excess of 52,000 and 135,000 sugarcane deliveries annually to process 1.25 and 3.5 million tons annually, respectively, resulting in a very high level of transaction frequency (5). In confirmation of this high level of frequency

Table 5

Supply chain contract characteristics for $2000 / 1$

Contract characteristic

Leveloftransaction characteristic

Mhlume Sugar Co.

Transvaal Sugar Co.

1. Frequency

2. Asset specificity

3. Uncertainty Abilitytowalk away from contract

Substitutes

Duration

Ex ante controls

Levelofexpost importance

Information shared

Contract enforcement

Average

5

5

3

5

3

5

5

3

3

4
5

5

3

5

3

5

5

3

3

4

an administration transaction is generated for every 246 tons and 582 tons delivered in the TSB and MSCo supply chains, respectively.

Very high levels of asset specificity (5) exist because the plant and assets of both companies are expensive ( $\mathrm{R} 2-2.3$ billion), they are industry and site specific, high levels of co-ordination are required and the assets have a low asset disposal value. The level of supply uncertainty is moderate to high because of the long time period of supply (10 years), the high degree of leverage of both companies induced by the fixed cost structure and because of high levels of downstream price volatility. Conversely, uncertainty is reduced by a lack of alternate opportunities for the farmers and a wide range of interlocking factors that includes high levels of company involvement in the growers affairs and communities. The presence of trust and mutual interest also appears to have reduced uncertainty. In view of the conflicting nature of factors influencing trust, a qualitative assessment of the overall level of supply uncertainty is graded at intermediate to high. The contract characteristic of uncertainty, however, is better quantified by analysing certain contract conditions of supply.

A summary of the actual contract conditions of sugarcane supply indicates that control is complex-internalised (3), there are no substitutes (5), the duration of the arrangement is 10 years or more (3), there is a low level of ex ante control (5), a high level of ex post importance (5) and a medium level of information (3) shared between the processor and the growers. Although contract enforcement can be influenced by legal means it relies more on the mutual interest of the 
parties. Contract enforcement is therefore complex-legal (3). There is also a limited ability to walk away (3) from the contract because of the long-term nature of sugar production which is grown on a 10 -year cycle.

\section{Should sugarcane production be outsourced?}

The central question that needs to be addressed is whether or not the Mhlume Sugar Company should unbundle its own company estates and outsource the supply of sugarcane on a specification contracting basis? A further question that needs to be asked is whether or not the Mhlume Sugar Company has chosen the correct outsourcing structure with respect to the sugarcane that is already outsourced on a specification contract basis? These research questions are tested by applying the methodology developed in Section 3.1 to the contract characteristics of sugarcane supply that have been developed and graded in Section 5. In Table 6 the actual contract characteristics of the MSCo and TSB cane supply operations $(\mathrm{a}-\mathrm{c})$ have been matched with one of five governance forms. For each company match a score of 1 is recorded in the relevant column with respect to each contract characteristic and a summary score for each column is calculated.

The actual contract characteristics of both the MSCo and TSB sugarcane supply operations indicate a high level of frequency (5) and a high level of asset specificity (5). In addition a summary of the contract characteristic of uncertainty (c) appears to range between intermediate and high. In more detail, a summary of uncertainty indicates that because of the long-term nature of sugarcane supply, in addition to the company involvement in the communities, there is a limited ability to walk away from the contract (3). Furthermore, there are no substitutes (5), the duration of the arrangement is intermediate to long (3), there is a low level of ex ante control (5), a high level of ex post importance (5) and an intermediate level of information shared (3) between the processor and the growers. Finally, contract enforcement with respect to outsourced production is complexlegal (3). 
Table 6

Matching Contract Characteristics with the Level of Managed Control

\begin{tabular}{|c|c|c|c|c|c|}
\hline \multirow[t]{4}{*}{ Contract characteristics } & Grade 1 & Grade 2 & Grade 3 & Grade 4 & Grade 5 \\
\hline & \multicolumn{5}{|c|}{ V.C. continuum } \\
\hline & \multirow{2}{*}{$\begin{array}{l}\text { Classical } \\
\text { Contracting } \\
\text { Spot Market }\end{array}$} & \multirow{2}{*}{$\begin{array}{l}\text { Neo classical } \\
\text { Contracting } \\
\text { Specification } \\
\text { Contracting }\end{array}$} & $\begin{array}{l}\text { Neo classical } \\
\text { Contracting }\end{array}$ & \multirow{2}{*}{$\begin{array}{l}\text { Bilateral } \\
\text { Relational } \\
\text { Formal Co- } \\
\text { operation }\end{array}$} & \multirow{2}{*}{$\begin{array}{l}\text { Unified Relational } \\
\text { Vertical Integration }\end{array}$} \\
\hline & & & $\begin{array}{l}\text { Strategic } \\
\text { Alliance }\end{array}$ & & \\
\hline (a) Frequency & Low & Low-medium & Medium & High & $\begin{array}{l}\text { Very high; } M S C o=52,350 ; \\
T S B=136,000\end{array}$ \\
\hline (b) Asset Specificity & Low & Low-medium & Medium & High & $\begin{array}{l}\text { Very high; } M S C o=\mathrm{R} 2 \\
\text { billion; } T S B=\mathrm{R} 2.3 \text { billion }\end{array}$ \\
\hline \multicolumn{6}{|l|}{ (c) Uncertainty } \\
\hline Ability to walk away & Yes & Yes/lower & Less $M S C o$ and $T S B$ & Low & No \\
\hline Substitutes & Yes & Yes/less & Less & No & No MSCo and TSB \\
\hline Duration & Short & Short-medium & $\begin{array}{l}\text { Medium } M S C O 10 \text { years; } \\
T S B 10 \text { years }\end{array}$ & Long & Very long \\
\hline Ex ante control & High & Lower & Low & No & No MSCo and TSB \\
\hline Ex Post Importance & Low & Low-medium & Medium & High & Very high MSCo and TSB \\
\hline Information Shared & Low & Low-medium & Medium MSCo and TSB & High & Extensive \\
\hline Contract Enforcement & Legal & Complex-legal & Complex $M S C o$ andTSB & Bilateral & Hierarchy \\
\hline Summary of contract characteristics & 0 & 0 & 8 & 0 & 10 \\
\hline
\end{tabular}

Based on: Williamson (1975, 1979, 1981), Mahoney (1992), Peterson and Wysocki (1997, 1998), Sartorius and Kirsten (2002). 
A summary of the aggregated entries in Table 6 suggests that the contract conditions are best matched with a governance form that ranges between a strategic alliance with a score of eight and full vertical integration with a score of 10 . There appears to be a marginally higher weighting towards full vertical integration (55\%) rather than a strategic alliance $(45 \%)$. Both of these governance forms imply that the sugarcane supply activities require a more relational contracting structure than specification contracting. The question is has the transaction cost approach made the correct decision that sugarcane supply should be co-ordinated by a more relational form of contract structure? If it is accepted that the firm can be represented by a 'nexus of contracts' and that sugarcane supply can be represented by some form of contract then, if the contract characteristics of sugarcane supply can be determined, transaction cost analysis can reliably predict the optimum contract structure. This observation is supported by an empirical success story (Masten, 1996; Williamson, 2000). On this basis sugarcane supply should not be outsourced as the case study indicates that the governance structure of the company estates are more suited to coordinating these activities. If this is the case, what has persuaded Mhlume Sugar to make the incorrect decision to outsource this raw commodity? Firstly, the Mhlume Sugar Company (MSCO) believes its core competencies are mostly located in the processing operation which also accounts for a majority of the profit in sugar manufacturing. This decision appears to ignore the fact that its $\mathrm{R} 2$ billion processing operation is intimately reliant on the localised source of a perishable raw commodity and that the plant and equipment demonstrate high levels of asset specificity. Secondly, there is tremendous social pressure on agribusiness in Southern Africa to contribute to the transformation of the agricultural sector by way of expanding smallholder supply arrangements. Thirdly, MSCO has ignored the differential transaction cost of smallholder supply because its costing systems were relatively unsophisticated and unable to trace overhead cost to different categories of supplier. This has resulted in the relevant cost of outsourcing being understated. Fourthly, the company has under estimated the future uncertainty of supply. The reason for this is that Swaziland, at least historically, received preferential prices for sugar, making sugarcane farming the most lucrative cash crop in the country. This was re-enforced by the fact that limited opportunities existed for farmers to grow alternate high value cash crops. Contracted farmers, therefore, have been locked into sugarcane production thus reducing the uncertainty of supply. The current situation in international sugar markets demonstrates unprecedented levels of price volatility and differential levels of regulation in the sugar industry in different sugar producing countries. In short, sugar production is becoming an increasingly risky industry. In response to the first research question, therefore, the transaction cost approach adopted by this study appears to make the correct decision not to outsource sugarcane supply. In this respect, the transaction cost framework suggests that the contract characteristics of supply are better managed by the internalised structure of the company estates than the more market co-ordinated structure of specification contracting. Conversely, the Mhlume Sugar Company decision to unbundle its own sugarcane supply activities by way of outsourcing these activities to small farmers is questionable and the company should continue to self-produce the maximum possible volume of sugarcane on its own company estates.

In response to the second research question, the results suggest that the Mhlume Sugar Company has not chosen the correct governance structure with respect to the supply of sugarcane that has already been outsourced on a specification contract basis (level 2). Quite clearly the supply of sugarcane should be co-ordinated by a more relational contracting structure than the neo-classical specification contracting arrangement. In this respect, the results suggest a governance form that 
ranges between a strategic alliance (45\%) and full vertical integration, with a higher weighting towards full vertical integration (55\%). Some form of hybrid structure, for example a strategic alliance, that leans towards a relational contracting arrangement is suggested as a minimum level of managed coordination. The contract characteristics, reflected in Table 6, appear to determine the minimum level of managed co-ordination, namely, a strategic alliance, more precisely than the maximum level. Quite clearly the spot market would be unable to coordinate and synchronise the real time supply of 1.27 million and 3.6 million tons, respectively, of a highly perishable product like sugarcane. The study, therefore, agrees with a large body of literature that has concluded that the spot market cannot be synchronised with respect to ensuring the continuous supply of a uniform quality raw commodity (Glover, 1984, 1994; Kilmer, 1986; Mahoney, 1992; Hennessy, 1996; Azzam, 1996). The use of specification contracting, in the absence of interlocking factors, is also not recommended as a way to co-ordinate the transaction characteristics of the sugar supply operations. In response to the second research question the conclusion can be reached that sugarcane supply should not be outsourced to small-scale suppliers by way of a specification contract but rather co-ordinated by way of a governance structure with higher levels of managed control.

\section{Discussion}

The results appear to confirm the conclusion of Roodhooft and Warlop (1999) and Joslin (2003) that high levels of asset specificity and opportunism are often incorrectly ignored in the outsource decision in the traditional management accounting literature. The results suggest the Mhlume Sugar Company appears to have outsourced sugarcane without due consideration of the high levels of asset specificity that exist. In this regard, the company appears to have concluded that the costs incurred with respect to the purchase of processing assets are a sunk cost that is not relevant. However, this assumption has ignored the possibility of other costs being incurred as a result of supplier opportunism developing as a response to the investment in these assets. The increased cost to the company of the supply arrangement, therefore, results from increased levels of uncertainty that have been introducedas a result of the outsourcer becoming increasingly dependent on the supplier. Furthermore, there is no guarantee that the sugarcane farmers will stay in the sugar industry if sugar prices drop. Currently, the Southern African sugar industry faces the serious threat that it cannot, for instance compete with many foreign sugar producers because their industries are subsidised.

The results expand the conclusions of Widener and Selto (1999) who suggest that the structure of an outsourcing arrangement can be based on combinations of frequency and asset specificity. The transaction cost framework (TCF), adopted by this study, suggests other contract characteristics influencing uncertainty can be combined with the contract characteristics of asset specificity and frequency in order to predict an optimum outsourcing structure. Alternatively, it can be used to test the reliability of a more traditional relevant costing approach. The results also complement the study of Van der Meer-Kooistra and Vosselman, (2000) who suggest that the choice of a specific organisation structure should consider the transaction environment and the specific characteristics of the parties. The methodology developed in Section 3.1 provides an alternative way to identify a specific structure and, to some extent, could assist to operationalise the conclusions of Widener and Selto (1999) and Van der Meer-Kooistra and Vosselman (2000). A limitation of the study with respect to the TCF approach adopted, however, is that the impact of interlocking factors has been largely ignored. Anderson et al. (2000) and Van der Meer-Kooistra and Vosselman (2000), for instance, infer that higher levels of trust can offset the influence of high asset specificity and that a 
hybrid structure involving trust can successfully co-ordinate activities that would need to be internalised where no trust exists. Trust-based inter-firm structures are often a suitable governance form where future contingencies are unknown, market risk is high, social embeddedness is a factor and institutional factors influence the relationship. Trust-based structures are also the most suitable when high levels of supplier competence and reliability are required. Since similar conditions persist in the case study the implication is that if the Mhlume Sugar Company could inculcate high levels of trust in the sugarcane supply chain then its level of supply uncertainty could be reduced. High levels of trust will be especially important if the company persists in employing specification contracting as a governance form to secure sugarcane supply. If higher levels of trust can be secured the company would be able to outsource sugarcane production on a more market-based structure than full vertical integration. In support of this contention, Anderson et al. (2000) conclude that the Japanese have been able to successfully employ less internalised structures because of higher levels of trust in supply chains.

The case study presents a similar contradiction as in the study of van den Bogaard and Spekle (2003) in that the strategy of the company has promoted the governance structure of outsourcing on a specification contract basis whilst the transaction characteristics of supply suggest the need for higher levels of managed control. More specifically, the company strategy has identified sugarcane supply as a potential non-core activity because profit in the sugar industry is largely earned in the processing operation. This assumption has been further complemented by the equity objective to promote smallholder supply. Quite clearly a combination of high levels of asset specificity, high fixed processing costs and the problem of coordinating large volumes of a highly perishable raw commodity, tend to suggest sugarcane supply is a core activity. The conclusion can be reached that the transaction characteristics of sugarcane supply have been partially ignored in the structure chosen by the case study and, therefore, the assumption of Coase (1937) that organisations gravitate towards structures that minimise cost is only true in specific sets of conditions and that these conditions cannot adequately assimilate equity objectives.

\section{Summary and conclusion}

The study commenced by discussing the increased incidence of outsourcing as a result of organisations shedding non-core activities. The increased incidence of outsourcing was also debated in agricultural supply chains before discussing some of the literature relating to the make versus buy decision. Transaction cost theory was then introduced so that the outsourcing decision could be analysed from a different perspective to the traditional management approach that focuses on a limited range of cost. A methodology was then developed to predict the most suitable governance form with respect to a set of contract conditions. Finally, a case study in the sugar industry was used to test the research questions.

The results and discussion of the study, with respect to the first research question, indicate that the company should not unbundle its own sugarcane supply activities in favour of outsourcing these activities to small-scale farmers because the contract characteristics of supply suggest the need for a more relational structure. The results suggest that the quantification of the relevant cost of outsourcing in the management accounting literature is inadequate because traditional management accounting systems do not highlight the total cost of outsourcing from both production and transaction cost perspective. This problem is further complicated if the costing systems of the organisation are unable to trace differential levels of transaction cost to different types of supplier. The usefulness 
of these results is that a transaction cost analysis approach has been employed to expand the traditional management accounting knowledge of the costs involved in the outsourcing decision. In particular, this study confirms that the traditional MA approach appears to be unable to identify all the costs that relate to uncertainty and asset specificity in the outsourcing decision. This study, therefore, contributes to the knowledge of outsourcing by way of developing an expanded transaction cost analysis methodology that can be used alongside traditional MA techniques, to determine the full cost of the make versus buy decision.

The results and discussion of the study with respect to the second research question suggest that the Mhlume Sugar Company should attempt to restructure the sugar supply agreement with respect to farmers who are already contracted to supply sugarcane to the company. The usefulness of the results is that a transaction cost approach can be employed not only with respect to making the decision to outsource or not but, once having made the decision, to optimally structure the outsourcing arrangement. The study makes a contribution to the knowledge of outsourcing by developing a comprehensive transaction cost analysis (TCA) methodology to identify the most appropriate structure of an outsourcing arrangement. More specifically, this methodology expands and combines previous attempts by Sidener and Welto (1999) and Van der Meer-Kooistra and Vosselman (2000) to implement a TCA approach to optimally structure an outsourced activity. In the case study, however, the question is also a matter of how the company can attempt to restructure the specification contract arrangement of existing suppliers. The question of expanding smallholder supply remains a contentious issue and a more durable and managed structure than specification contracting is suggested. The discussion indicates how certain interlocking factors can contribute to reducing the uncertainty of supply and, as a result of this, promote the suitability of a neo-classical contract structure, like specification contracting, for long-term supply arrangements that require high levels of managed control. This assumption is consistent with transaction cost theory and could be achieved by some type of trust-based hybrid structure where mutual asset specificity is nurtured. Solving this problem could reduce supply uncertainty caused by opportunism and convert the governance form of specification contracting into a form of strategic alliance. For example if the company forms a strategic alliance with a farmers' association that has invested in growingharvesting technology that is sugar specific then both partners would tend to share a more common time horizon and the exit costs would be raised for both parties.

Finally, the results and discussion of the study demonstrate how transaction cost theory can contribute to a better understanding of the relation between strategy and structure, as well as contribute to a better understanding of a firm's core versus non-core activities. This knowledge, in turn, can be employed to decide the boundaries of the firm. The results suggest that Mhlume Sugar Company has, perhaps, incorrectly classified sugarcane production as a non-core activity because company profitability is largely generated by the manufacturing operations. The classification of sugarcane supply as a non-core activity also complements the equity objectives of the company to expand the commercialisation of small farmers. The usefulness of the results is that a transaction cost approach can be employed to test the soundness of structures that emanate from company strategy and that that a resource-based strategy may incorrectly structure certain activities.

In conclusion, this study highlights a dilemma for agribusiness in South Africa, namely, an equity responsibility to assist the expansion of smallholder-previously disadvantaged supply versus the incremental transaction cost of supply. Successfully managing and negotiating an outsource transaction in these conditions entails co-ordinating a diverse group of internal stakeholders like IT, finance, human resources with outside experts. In order to strengthen the conclusions of this study 
future research is required to expand the application of the transaction cost methodology to the outsourcing of goods and services in other industry sectors. Finally, further research is needed with respect to how interlocking contract conditions, like mutual interest and trust, can be developed in neoclassical contracting arrangements in order to promote a more relational arrangement.

\section{Acknowledgements}

I would like to thank the Mhlume Sugar Company, the Transvaal Sugar Company and The South African Cane Growers Association for their assistance. In particular, I would like to thank Tom Lupton, Gavin Kruger, Mike Lyne, Brian Sugden, Adrianne Wyn, Louise Fenwick and Bigman Maloa. More specifically, I would like to thank my colleague Minga Negash, the two reviewers and the extensive input of Bob Scapens

\section{References}

Abernathy, M.A., Lillis, A.M., 2001. Interdependence in Organization design: a test in hospitals. J. Manage. Acc. Res. 13 (23), 107-129.

Anderson, S.W., Glenn, D., Sedatole, K.L., 2000. Sourcing parts of complex products: evidence on transactions costs, high powered incentives and ex-post opportunism. Acc. Organ. Society 28 (8), 723-727. Anthony,

R.J., Govindarajan, V., 2001. Management Control Systems. Prentice Hall.

Azzam, A., 1996. Testing the monopsony-inefficiency incentive for backward integration. Am. J. Agr. Econ. 78 (3), $585-591$.

Barney, J.B., Ouchi, W.G., 1988. In: Barney, J.B., Ouchi, W.G. (Eds.), Organization Economics. Jossey-Bass Publishers, San Francisco.

Baumol, W.J., 1997. Musings on vertical integration. International Journal of Social Economics 24 (1-3), 12-16.

Burns, J., Scapens, R.W., 2000. Conceptualizing management accounting change: an institutional framework. Manage. Acc. Res. 11 (1), 3-27.

Coase, R.H., 1937. The nature of the firm, 4 Economica, N.S. 386.

Colchao, S., 1999. Will AG Banks prosper in age of vertical integration. ABS Banking J. 91 (11), 26-31.

Cutts, R., 1992, July-August. Capitalism in Japan. Harvard Bus. Rev., 48-55.

Demsetz, H., 1988. The theory of the firm revisited. J. Law Econ. Organ. 4 (1).

Foss, P. (Ed.), 1995. Economic Approaches to Organizations and Institutions. Dartmouth, Sydney.

Frank, S.D., Henderson, D.R., 1992. Transaction costs as determinants of vertical co-ordination in the U.S. food industries. Am. J. Agr. Econ. 74 (4), 941-950.

Glover, D., 1984. Contract Farming and smallholder outgrower schemes in less developed countries. World Devel. 12 (11), 1143-1157.

Glover, D., 1994. Contract farming and commercialization of agriculture in developing countries. In: Von Braun, J., Kennedy, E. (Eds.), Agricultural Commercialization, Economic Development and Nutrition. The John Hopkins University Press, Baltimore, MD.

Groenewegen, J., 1996. In: Groenewegen, J. (Ed.), Transaction Cost Economics and Beyond. Kluwer Academic Publishers, Boston.

Hayes, D., Hayenga, M., Thompson, S.J., 2000. Transaction cost economics and the evolving structure of agricultural production. In: IAMA World Food and Agribusiness Congress, Chicago, Illinois.

Hennessy, D.A., 1996. Information asymmetry as a reason for vertical integration. Am. J. Agr. Econ. 78 (40), $034-044$.

Hobbs, J.E., Young, L.M., 1999. Increasing vertical linkages in agrifood supply chains: a conceptual model and some preliminary evidence. Paper presented at the Canadian Agricultural Economics Society and the World Agricultural Economics Society, Fargo, North Dakota, July 10-14.

Joslin, R., 2003. Why does the contract price differ from the RFP price? Outsourcing J (Copyright 2003-Everest Partners. L.P. 
Dallas).

Khalil, E.L., 1996. After the special nature of the firm. In: Groenewegen, J. (Ed.), Beyond the Crisis of Orthodox Neoclassical Economics. Kluwer Academic Publishers, Boston.

Kilmer, R.L., 1986. Vertical Integration in agricultural and food marketing. Am. J. Agr. Econ. 68 (5), $1155-1161$.

Klein, B., Crawford, R.G., Alchian, A.A., 1988. Vertical integration, appropriate rents and the competitive contracting process. In: Barney, J.B., Ouchi, W.G. (Eds.), Organization Economics. Jossey-Bass Publishers, San Francisco.

Langfield-Smith, K., Smith, D., 2003. Management control systems and trust in outsourcing relationships. Manage. Acc. Res. 14 (3), 281-307.

Mahoney, J.T., 1992. The choice of organizational form: vertical financial ownership versus other methods of vertical integration. Strategic Manage. J. 13, 559-584.

Mahoney, J.T., Pandian, J.R., 1992. The resource based view within the conversation of strategic management. Strategic Manage. J. 13, 363-380.

McAfee, R.P., 1999. The effects of vertical integration on competing input suppliers. Econ. Rev. (Federal Reserve Bank of Cleveland) 35 (1), 2-7.

Merchant, K.A., 1998. Modern Management Control Systems. Prentice Hall, New Jersey.

Pasour, E.C., 1998. The potential impact of increased vertical integration on North Carolina grain farmers. North Carolina State University, http://www.ncsoy.org/pasour2.htm.

Peterson, H.C., Wysocki, A., 1997. The vertical coordination continuum and the determinants of firm-level coordination strategy. Staff Paper 97-64, Michigan State University.

Peterson, H.C., Wysocki, A., 1998. Strategic choice along the vertical co-ordination continuum. Staff Paper 98-16, Michigan State University, East Lansing, Michigan 48824.

Rehber, E., 1998. Vertical integration in agriculture and contract farming. Regional Research Project NE-165: Private Strategies, Public Policies, and Food System Performance, University of Massachusetts, Department of Resource Economics, Amherst, MA 01003. Reve, T., 1995. In: Foss, P. (Ed.), The Firm as a Nexus of Internal and External Contracts.

Dartmouth, Sydney.

Rhodes, V.J., 1993. Industrialization of agriculture: discussion. Am. J. Agr. Econ. 75 (5), 1137-1140.

Ring, P., van den Ven, A., 1992. Structuring cooperative relationships between organizations. Strategic Manage. J. 13, $483-498$.

Roodhooft, F., Warlop, L., 1999. On the role of sunk costs and asset specificity in outsourcing decisions: a research note. Acc. Organ. Society 24 (4), 363-367.

Rowlinson, M.J., 1997. Organisations and Institutions. Macmillan Press, London. Royer, J.S., 1995. Potential for cooperative involvement in vertical coordination and value added activities. Agribusiness 11 (3), 473-481.

Ruth, M., Cloutier, L.M., Garcia, P., 1998. A non-linear model of information and coordination in hog production; testing the Coasian-Fowlerian dynamic hypotheses. Paper: American Agricultural Economics Association, Salt Lake City, UT, August 2-5.

Sartorius, K., Kirsten, J.F., 2002, December. Can small-scale farmers be linked to agribusiness? The timber experience. Agrekon.

Schrader, L.F., Boehlje, M., 1996. Co-operative co-ordination in the Hog-Pork system: examples from Europe and the U.S. Staff Paper 96-21, Purdue University, Department of Agricultural Economics, Indiana.

Seifert, E.K., Priddat, B.P., 1995. The Transaction Cost Approach to New Institutional Economics: A Generalization and Critique. Marburg, http://www.wiwi.uni-regensburg.de/.

Spekle, R.F., 2001. Explaining management control structure variety: a transaction cost economics perspective. Acc. Organ. Society $25(4 / 5), 419-423$.

Van den Bogaard, M.A., Spekle, R.F., 2003. Reinventing the hierarchy: strategy and control in the Shell Chemicals carve-out. Manage. Acc. Res. 14, 79-93.

Van der Meer-Kooistra, J., Vosselman, G.J., 2000. Management control of interfirm transactional relationships: the case of industrial renovation and maintenance. Acc. Organ. Society 25 (1), $27-51$.

Vosselman, G.J., 2002. Towards horizontal archetypes of management control: a transaction cost economics perspective. Manage. Acc. Res. 13, 131-148.

Widener, S.K., Selto, F.H., 1999. Management control systems and boundaries of the firm: why do firms outsource internal auditing activities? J. Manage. Acc. Res. 11, 29-45.

Williamson, O.E., 1975. Markets and Hierarchies. Free Press, New York.

Williamson, O.E., 1979. Transaction cost economics: the governance of contractual relations. J. Law Econ. 22 (2), $233-261$.

Williamson, O.E., 1981. The economics of organization: the transaction cost approach. Am. J. Sociology 87, 548-577. 
Williamson, O.E., 1988. The logic of economic organization. J. Law Econ. Organ. 4 (1).

Zylbersztajn, D., Farina, E., 1999. Strictly coordinated food systems: exploring the limits of the Coasian Firm. Int. Food Agribus. Manage. Rev. 2 (2), 249-265 (ISSN: 1096-7508). 